\title{
Jogos On-line e Apps para consolidação dos princípios da contagem
}

\author{
Elenice Adriana dos Santos \\ E.B.Paulo Bauer \\ Itajaí SC Brasil \\ eleniceadrianaquimica@gmail.com
}

\author{
Patrícia Rodrigues Botelho \\ ECIM Melvin Jones \\ Itajaí SC Brasil \\ patrícia.tavares.botelho@gmail.com
}

\author{
André Raabe \\ Lab. de Inovação \\ Tecnológica na Educação \\ Universidade do Vale do Itajaí \\ Itajaí SC Brasil
}

\section{RESUMO}

Este artigo tem como objetivo apresentar um estudo experimental de intervenção em princípios da contagem, de modo a investigar a eficácia dos jogos didáticos virtuais e aplicativos como auxiliares. O processo de desenvolvimento matemático de uma criança se dá de maneira contínua e progressiva habilitando o indivíduo à capacidade de contar com sucesso devido a consolidação dos Princípios da Contagem, que são a correspondência termo a termo, a ordem estável, a cardinalidade, a irrelevância da ordem e a abstração. Quando dificuldades se apresentam ou os princípios não são consolidados, geram uma lacuna na aprendizagem matemática, ferramentas virtuais podem ser utilizadas como estratégia de ensino, estas ferramentas vêm na forma de jogos e apps que devem ser adequados e cumprirem efetivamente 0 papel de auxiliares na aprendizagem dos Princípios da Contagem; mas o uso da ferramenta não está condicionado somente a problemas de aprendizagem, pois as ferramentas digitais podem ser usadas a todo momento, durante o processo educacional de um indivíduo, basta ter um propósito lógico. Para tanto, se faz necessário analisar a real eficiência destes jogos e apps, que é o objetivo deste estudo, o qual será desenvolvido através de pesquisa de estudo de caso, de natureza aplicada, com o intuito de gerar informações sobre as ferramentas e a sua eficácia na consolidação dos princípios da contagem. A pesquisa será aplicada com uma aluna de 7 anos matriculada no $1^{\circ}$ ano do ensino fundamental. Espera-se, com este estudo, responder à questão: Os Jogos Virtuais auxiliam na consolidação das habilidades relacionadas aos Princípios da Contagem na alfabetização matemática?

\section{PALAVRAS CHAVE}

Aprendizagem Matemática, Jogos educativos, Princípios da contagem.

\section{INTRODUÇÃO}

Os números e sua contagem, sua leitura, sua escrita e a sua interpretação são habilidades que se apresentam muito cedo, quando as crianças, ainda não alfabetizadas, já são estimuladas a interpretar e compreender os seus significados. $A$ arte de contar e entender a contagem requer uma sequência de informações que vem desde a educação infantil, com o auxílio de músicas e brincadeiras que resultam num amadurecimento cognitivo da criança a partir dos 3 a 4 anos de idade, tornando-a hábil a reconhecer simbolicamente os números e sua representação através de materiais concretos diversos. Entendemos então que contar não é simplesmente repetir uma sequência e sim associar um valor, número, a uma quantidade concreta de materiais ou objetos. A partir da préescola da Educação infantil início da sua vida escolar são introduzidos e a criança começa a 
apropriar-se dos Princípios da contagem, a saber:

- correspondência termo a termo - cada objeto pode ser contado somente uma vez sendo utilizado um nome de número.

- ordem estável - a ordem das palavras de contagem é invariante, seguindo a sequência, ou contar a partir de.

- cardinalidade - o total de objetos de um conjunto corresponde ao último nome de número, sendo que este envolve todos os números da sequência.

- irrelevância da ordem - objetos de um dado conjunto podem ser contados em qualquer ordem.

- abstração - objetos de qualquer natureza podem ser contados juntos. Princípios estes que foram formulados inicialmente por Gelman \& Gallistel [1] e discutidos posteriormente em diversos estudos.

De acordo com Piaget e Szeminska [7] a criança constrói progressiva e interiormente a capacidade de contar com sucesso os objetos e essa capacidade só está consolidada quando ela consegue coordenar várias ações sobre os objetos (classificação, seriação, correspondência, entre outras), a fim de quantificá-los.

Em relação à contagem, é possível, ainda, analisar as estratégias e os procedimentos utilizados pelas crianças. Entre as estratégias, Geary [8] identifica a contagem verbal, a contagem nos dedos, a decomposição e a recuperação imediata, e no que se refere aos procedimentos, identifica o "contar todos" e o "contar a partir de", considerando que o primeiro envolve contar as duas parcelas e depois realizar o cálculo enquanto o segundo consiste em iniciar a contagem pela parcela maior e seguir contando a outra parcela.

Há crianças que dentro desse espaço de tempo destinado ao desenvolvimento e aquisição dos Princípios da contagem apresentam dificuldades ou apenas não consolidam os princípios, gerando uma lacuna na aprendizagem matemática que perdurará por toda a vida escolar. A fim de amenizar esta situação, ferramentas do tipo virtual foram utilizadas como estratégia de ensino, na forma de jogos didáticos e apps.

A compreensão matemática, em qualquer idade da vida de um indivíduo, se dá com a aquisição de conceitos matemáticos que fazem parte de inúmeras habilidades adquiridas e desenvolvidas com o passar dos anos; dentre essas habilidades está o Princípio da Contagem o qual permitiu à criança desenvolver a compreensão, interpretação e aquisição dos conceitos referentes aos números e suas representações, fatores determinantes para 0 sucesso da aprendizagem matemática durante todas as etapas de ensino.

Os Princípios da Contagem quando bem trabalhados, desenvolvem na criança o real conceito de número, sua representação gráfica é quantitativa, não sendo uma mera contagem, mas sim a associação entre o registro numérico e quantidade que representa.

Os 5 (cinco) Princípios da Contagem devem estar bem desenvolvidos até o $2^{\circ}$ ano do Ensino Fundamental I, porque nesta etapa a criança já possui maturidade para compreendê-los, infelizmente, temos crianças que, por vários motivos, não se apropriam desses Princípios, tornando-se este, um grande problema na aquisição de novos conceitos.

É fato que, como ferramenta de auxílio, muitos professores recorrem a jogos didáticos virtuais e apps com a finalidade de auxiliar a compreensão de conteúdos ensinados e muitas vezes não conseguem encontrar o material ou, quando encontram, não correspondem à finalidade da procura. Então, visando poder sugerir ferramentas que auxiliem na aquisição destes conceitos matemáticos, este artigo teve como objetivo auxiliar na seleção de jogos virtuais que contribuíram na compreensão dos Princípios da Contagem a fim de obter subsídios que permitiram analisar a sua efetividade enquanto ferramentas de auxílio na consolidação destes conceitos.

Vale lembrar de que os jogos didáticos e apps são instrumentos voltados a vários propósitos e um deles é o reforço na aprendizagem, mas, estes além de ter a variável do entretenimento, tem propósito social, ligando pessoas em competições, por exemplo, são usados na 
segurança de comunidades, na segurança pessoal com aplicativos médicos, na administração econômica, no mercado habitacional, etc. Tanto os jogos didáticos como os apps devem ser funcionais, ou seja, atender à necessidade para a qual foram criados.

Analisar esta funcionalidade foi o objetivo deste estudo, pois, eles devem atender aos propósitos de proporcionar ao usuário meios de aquisição e consolidação dos Princípios da Contagem.

Para auxiliar na avaliação foi conduzido um estudo de caso com uma aluna do $1^{\circ}$ ano do ensino fundamental I, do município de Itajaí/SC, que foi submetida ao desenvolvimento de atividades analógicas de raciocínio, permitindo assim, constituir uma análise da qualidade do desempenho alcançado pelos sujeitos nesta fase do estudo.

Posteriormente, a aluna foi submetida a resolução de atividades através do meio virtual de jogos didáticos e apps onde foi avaliado o seu desempenho lógico, frente aos desafios propostos no que se refere a interpretação de situações que envolviam os cinco princípios da contagem visando 0 aprofundamento da compreensão e verificação da eficiência e funcionalidade destes jogos e apps. A contribuição está em criar uma coleção de jogos e apps que demonstrem sua funcionalidade cumprindo com o propósito de auxiliarem na compreensão dos Princípios da Contagem justificando a sua utilização com eficácia no auxílio à aprendizagem.

\section{FUNDAMENTAÇÃO TEÓRICA}

Nos anos iniciais, dá-se uma grande importância na construção do conceito de número pela criança, pois essa será a base para a aprendizagem da matemática nas séries futuras. "O número é a relação criada mentalmente por cada indivíduo" PIAGET apud KAMII [2].

Os princípios de contagem na matemática são de fundamental importância para a resolução dos desafios cotidianos. A matemática na vida se apresenta como um problema real, exigindo a criação de possibilidades e estratégias diversas a todo instante. Sem habilidades matemáticas bem desenvolvidas, os alunos não conseguem realizar atividades importantes da vida cotidiana. NUNES e BRYAN, 1997[5].

Muitas são as dificuldades enfrentadas pelos professores no ensino dos princípios de contagem matemática, dentre elas está o desafio de evidenciar a presença dos números na vida real, e relacionar ao conteúdo ensinado na escola. Ensinar matemática é ensinar a compreender o mundo ao redor, ou seja, fazer mais do que uma simples contagem. Embora a mídia digital (internet) disponibiliza muitas propostas de jogos didáticos e apps, a ferramenta só será adequada se efetivamente cumprir seu papel auxiliando na aprendizagem, para tanto, se faz necessário analisar a real contribuição que os jogos didáticos e apps trazem quando nos referimos a consolidação dos Princípios da contagem, sendo esta análise o principal objetivo do estudo, que será desenvolvido através de estudo de caso no método de análise qualitativa, de natureza aplicada, objetivando gerar conhecimentos na aplicação e prática de jogos didáticos e apps que apresentarem, através de análise , o intuito de auxiliar na consolidação dos princípios da contagem. Trabalhando os princípios de contagem de forma lúdica, pode-se facilitar a comunicação, socialização e construção do conhecimento do aluno, ainda mais se as atividades Jogos On-line e Apps para consolidação dos princípios da contagem forem aplicadas através de jogos didáticos virtuais e apps. O estudante instintivamente sentirá mais vontade de se envolver na atividade tornando-a agradável, motivadora e rica em conhecimento. O processo de quantificar, de descobrir a quantidade de números, acontece desde os anos iniciais, na infância do aluno, quando esse consegue representar o número de objetos ou símbolos de um conjunto, agrupando-os e descobrindo assim a sua quantidade, se tem mais, menos, ou igual, ou seja, é feito uma relação do objeto físico com o mental (os números). Para Kamii [2], "quantificar é a capacidade da criança representar um número com símbolos ou signos a partir de sua construção lógico matemática". Muitas situações diárias possuem uma necessidade significativa 
de fazer com que a pessoa relacione imagem à quantidade, então dentro de sala de aula é necessário que o professor incentive seus alunos para que por si só consigam resolver esses problemas. O Ministério da Educação divulgou no segundo semestre de 2012, atualizado com os resultados da Prova Brasil 2011, o "Quinto Relatório de Monitoramento das 5 Metas" [9], que aponta para uma situação preocupante em relação ao nível de proficiência dos alunos em relação aos conteúdos matemático, segundo 0 relatório conforme aumenta o nível de exigências das habilidades diminui a porcentagem de alunos que atingem os mesmos. O jogo didático apresenta um caráter construtivo, ele permite considerar a descentração da criança, para analisar o jogo também da perspectiva do outro, pensando em quais estratégias o outro pode estar planejando ou quais estratégias ele já utilizou que podem ser boas para o seu próprio jogo. Essa situação permite o erro, a tentativa, sem que haja um roteiro pronto, o caminho se cria ao longo do processo, sendo descoberto e recriado também a partir do outro [10].

Tentar de novo, persistir e suportar a frustração faz parte da brincadeira. A conscientização de que essas habilidades são necessárias mostra na prática, que é preciso continuar o jogo ou de que tudo pode mudar na próxima rodada. Observando também a necessidade da nova tentativa para o seu aperfeiçoamento como jogador, no jogo é possível ainda que a criança treine a antecipação da consequência, pois, ela precisa pensar antes de agir/jogar, planejar as suas ações visando bons resultados, fazendo com que compreenda o conceito de antecipação na prática [10].

\section{METODOLOGIA}

A pesquisa relatada aqui baseia-se em estudo de caso desenvolvido através de abordagem qualitativa, de caráter exploratório, quanto aos objetivos, é de natureza aplicada, o que segundo YIN [6] investiga um fenômeno contemporâneo em profundidade e em seu contexto de vida real, especialmente quando os limites entre 0 fenômeno e o contexto não são claramente evidentes".

Este estudo de caso foi desenvolvido através de pesquisa de análise qualitativa, pois visava 0 aprofundamento da compreensão através da utilização de jogos didáticos virtuais para auxiliar na consolidação das habilidades relacionadas aos princípios da contagem, permitindo verificar a eficiência e funcionalidade destes jogos didáticos e apps.

O estudo ocorreu entre os meses de agosto, setembro, outubro e novembro de 2020 , e para a participação na pesquisa e estudo de caso, foi selecionada uma criança através do critério de proximidade das graduandas, devido a situação de pandemia que vivemos neste momento. O sujeito participante foi uma aluna, do $1^{\circ}$ ano do ensino fundamental I, matriculada em escola da cidade de Itajaí/SC que foi observada pelo período de 1 (uma) hora, duas vezes por semana durante os meses citados.

Borin [3] define que quando a criança está dentro da situação de jogo, onde é impossível uma atitude passiva e a motivação é grande, nota-se que, ao mesmo tempo em que estas crianças falam "matemática", apresentam também um melhor desempenho e atitudes mais positivas frente a seus processos de aprendizagem, com base nesta definição inicialmente utilizaremos como instrumento de avaliação e sondagem um jogo de teste de conhecimento numérico.

Ainda conforme Borin [3], a pesquisa é de natureza aplicada, objetivando gerar conhecimentos na prática de jogos didáticos virtuais e apps que apresentarem, através de análise, o intuito de auxiliar na consolidação dos princípios da contagem. Apresenta cunho exploratório, com o objetivo de construir hipóteses sobre a utilização dos jogos a serem analisados, caracterizada pelas investigações através da realização de coleta de dados por meio de práticas de observação estruturada do indivíduo.

Conforme Gil [12] a observação é um "[...] elemento fundamental para a pesquisa [...] chega a ser mesmo considerada como método de investigação." Toda a análise inicia-se com a 
observação do tipo estruturada onde registra-se a forma como a aluna realiza as atividades, sejam elas impressas, em forma de brincadeiras propostas, ou na forma de desafios de contagem de objetos, a fim de descobrirem a quantidade de elementos em cada conjunto.

\section{ANÁLISE E DISCUSSÃO}

A escolha por trabalhar com jogos didáticos virtuais apoia-se nas interpretações de teóricos da abordagem de conceitos da perspectiva histórico-cultural de Vygotsky [13], e a proposta de ensino colaborativo de Fontes [11] que acreditam que dessa forma a aprendizagem é concebida de forma significativa, principalmente na fase escolar.

Conforme a Base Nacional Comum Curricular (BNCC) [4] a competência 5 (cinco) reconhece o papel fundamental da tecnologia e estabelece que o estudante deve dominar o universo digital, sendo capaz, portanto, de fazer um uso qualificado e ético das diversas ferramentas existentes e de compreender o pensamento computacional e os impactos da tecnologia na vida das pessoas e da sociedade.

Competência 5 : Compreender, utilizar e criar tecnologias digitais de informação e comunicação de forma crítica, significativa, reflexiva e ética nas diversas práticas sociais (incluindo as escolares) para se comunicar, acessar e disseminar informações, produzir conhecimentos, resolver problemas e exercer protagonismo e autoria na vida pessoal e coletiva [4].

A utilização desses jogos e aplicativos revelaram a sua eficiência, ou não, ao seu propósito de consolidação dos Princípios da Contagem; nesta fase do estudo, que levantamos questionamentos sobre as ferramentas sugeridas e elencamos as possíveis soluções para os problemas encontrados, e sugerimos os jogos que realmente podem auxiliar para a consolidação das habilidades relacionadas aos Princípios da Contagem. As observações realizadas pelo professor responsável serão utilizadas como forma de coleta de dados e serviram como informações base no processo, ou seja, a observação respondeu a perguntas como:

1 - O jogo permite que o aluno quantifique os objetos?

2 - O jogo permite que o aluno ordene os números corretamente?

3 - O jogo permite que o aluno faça a correspondência do número contado com o total de objetos?

4 - O jogo permite que o aluno relacione que a disposição dos objetos ou ausência dos mesmos não altera seu valor?

5 - O jogo pode ser utilizado como ferramenta estratégica de ensino/aprendizagem?

As práticas utilizadas, capazes de identificar as dificuldades referentes à apropriação dos conceitos voltados à contagem numérica, foram separadas em níveis e trabalhados a cada quinzena, estas práticas estabelecerão níveis de informação capazes de quantificar as dificuldades referentes à apropriação dos conceitos voltados à contagem numérica. A seguir são apresentados os softwares identificados conforme os princípios da contagem que atendem.

1 Princípio da Contagem - Correspondência termo a termo: cada objeto pode ser contado somente uma vez sendo utilizado um nome de número.

Quadro 1 - Ferramentas analisadas para o $1^{\circ}$ Princípio

Aprender a escrever os números de 0 a 10 https://www.cokitos.pt/aprender-a-escrever-osnumeros-de-0-a-10/play/

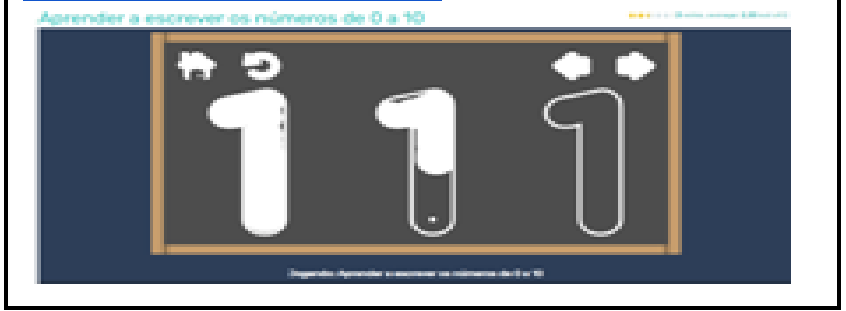


Este aplicativo é muito útil, mas somente para crianças bem pequenas entre 3 e 4 anos, crianças não alfabetizadas.

\section{Aprenda a contar | Escola Games - Jogos Educativos}

http://www.escolagames.com.br/jogos/aprenda Contar/

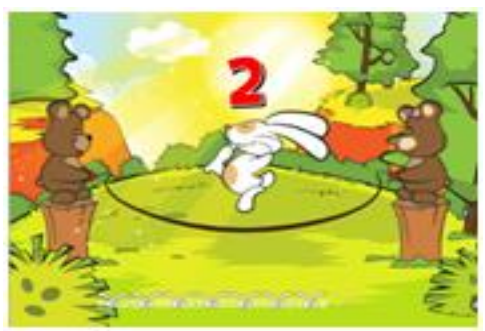

Este aplicativo cumpre o seu propósito, a contagem em sequência, porém é uma atividade cansativa, tempo de jogo muito longo que começa e termina do mesmo modo, não sendo atrativo para as crianças.

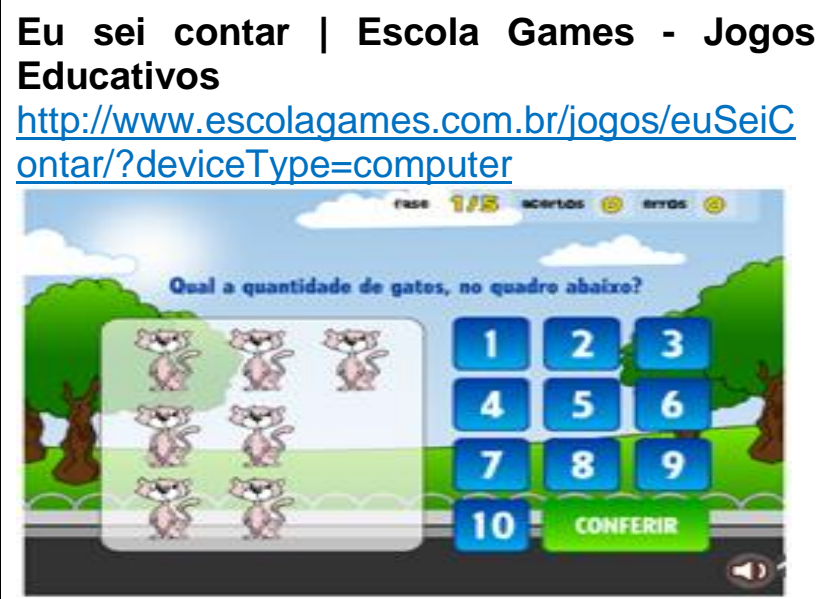

Este jogo é composto de 2 desafios, denominado missão, que tornam mais interessante a utilização da ferramenta e sua proposta permite que as crianças estabeleçam relações entre os números de 1 a 10 e construam hipóteses acerca de suas grandezas a partir da comparação. Durante o jogo, recitar a sequência e reconhecer cada um dos números é um desafio que propõe a fixação dos conhecimentos já adquiridos.

Esta ferramenta realmente cumpre o que propõe e atende aos objetivos de aprendizagem traçados, desde que a criança seja alfabetizada para ler o problema proposto e entender a lógica do aplicativo.

2 Princípio da Contagem - Ordem estável: a ordem das palavras de contagem é invariante, seguindo a sequência, ou contar a partir de.

\section{Quadro 2 - Ferramentas analisadas para o 20 Princípio}

\section{Antecessor e Sucessor na Fazenda}

https://www.jogosdaescola.com.br/antecessore-sucessor-na-fazenda/

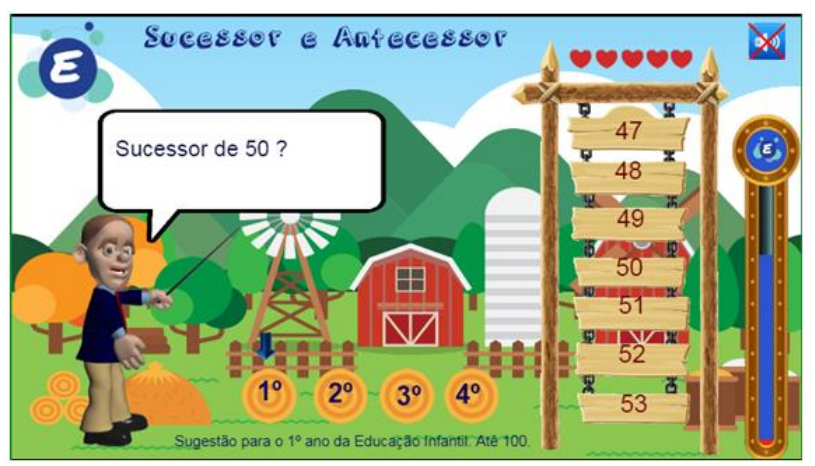

O aplicativo trabalha os conceitos "antecessor e sucessor" estimulando o desenvolvimento do raciocínio lógico das crianças e incentivando a elaboração de estratégias para resolver os desafios.

No caso de ocorrer uma resposta errada, o aplicativo apenas indica o erro, e dá a chance de novas tentativas, o que pode ajudar a criança a rever e aprender com o seu erro. $\mathrm{O}$ jogo é direcionado para crianças do $1^{\circ}, 2^{\circ}, 3^{\circ}$ e $4^{\circ}$ anos.O aplicativo não é atrativo, é cansativo e seus objetivos são trabalhados, mas não estimulam, nem atrai a atenção de alunos com dificuldade de aprendizagem, ela logo enjoa e pede para mudar; então, não corresponde ao propósito de ser utilizado com estratégia de aprendizagem.

Quiz Antecessor e Sucessor

https://wordwall.net/pt/resource/8004439/antec essor-e-sucessor 


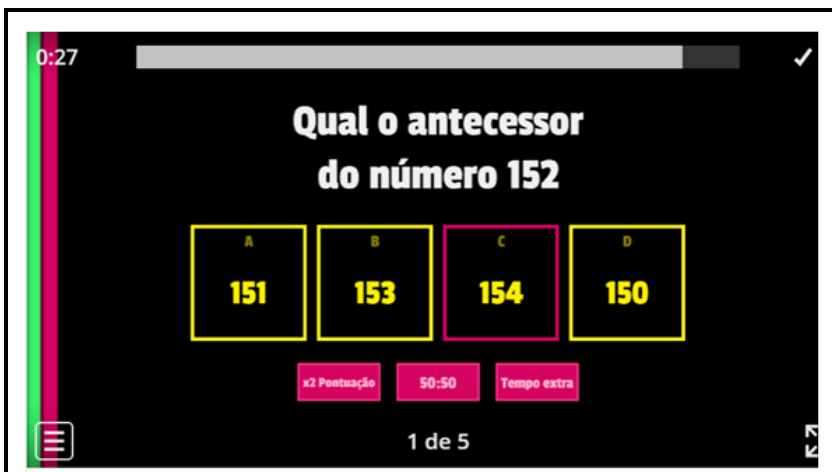

Este aplicativo cumpre o seu propósito, que é identificar o antes, o depois e o entre, em uma sequência, porém, seu nível de dificuldade requer uma criança alfabetizada ou intervenção de um instrutor, pois, o tempo de resposta para uma criança do 1ํ ano precisa ser maior. O ponto positivo do aplicativo está na apresentação das respostas, proporcionando ao aluno verificar seu erro. Ponto negativo está na falta de atualização de questões. O programa também apresenta uma tabela de classificação tornando possível a competição entre pares ou equipes maiores. O aplicativo corresponde ao propósito de ser utilizado com estratégia de aprendizagem.

\section{Roda Aleatória}

https://wordwall.net/pt/resource/7226341/antec essor-e-sucessor

Arraste a roda para girar

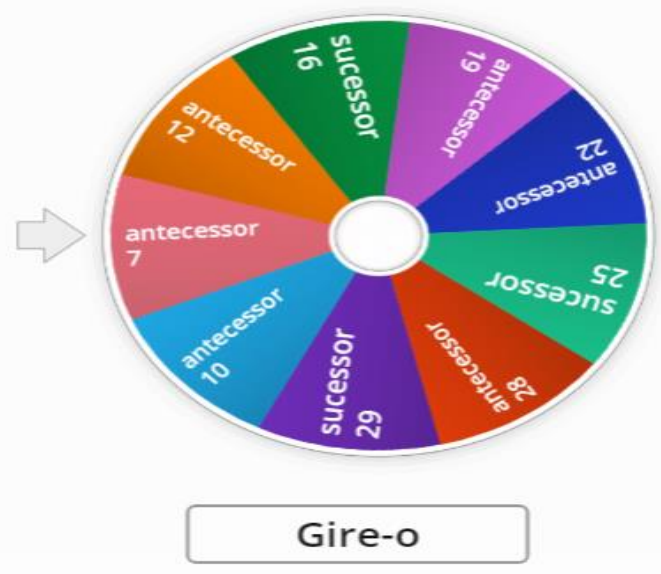

Este aplicativo cumpre o seu propósito, que é identificar o antes, o depois e o entre, em uma sequência. É um aplicativo indicado para atividades em pares ou competição oral, já que depende da memorização dos conceitos, Seu nível de dificuldade é compatível a qualquer ano/série permitindo a adaptação dos desafios. Crianças alfabetizadas ou não podem utilizar este aplicativo que pode ser adaptado.

O ponto negativo do aplicativo está na necessidade de construir as regras conforme adaptação.

3ํㅗㅅ́ㅁio da Contagem - Cardinalidade: 0 total de objetos de um conjunto corresponde ao último nome de número, sendo que este envolve todos os números da sequência.

\section{Quadro 3 - Ferramentas analisadas para o 3ำ \\ Princípio}

\section{Calculando}

https://www.jogosdaescola.com.br/calculando/

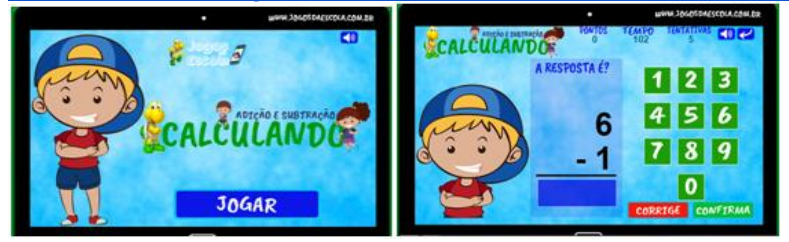

Este aplicativo cumpre com seu propósito proporcionando, a criança, desenvolver raciocínio lógico matemático, atenção, concentração e compreender o processo da adição e subtração. $O$ aplicativo disponibiliza níveis de dificuldade, que possibilitam a sua utilização para várias faixas de idade.

O jogo é auto explicativo, porém, se houver uma criança com dificuldade na interpretação de leitura um instrutor deve estar próximo para auxiliá-la.

Ponto positivo do aplicativo indica a resposta errada e dá a chance de refazer o desafio 5 vezes, pois tem um tempo regular para que a resposta seja dada pelo aluno, permitindo-o pensar e até usar de material concreto para efetivar a resposta a ser dada, proporcionando aprendizagem. 
O programa também pode ser utilizado para atividades em pares ou equipes, necessitando de poucas adaptações.O aplicativo corresponde ao propósito de ser utilizado com estratégia de aprendizagem.

\section{Calcule e Pinte}

https://www.smartkids.com.br/jogoseducativos/matematica-calcule-e-pinte

Este aplicativo cumpre com seu propósito proporcionando, a criança, desenvolver raciocínio lógico matemático, atenção, concentração e compreender o processo da adição e subtração. $\mathrm{O}$ aplicativo disponibiliza vários desafios com design diferenciado, mas não apresenta um aumento da dificuldade, o que produz desinteresse por parte dos alunos. A utilização deste aplicativo prioriza alunos do pré e do $1^{\circ}$ ano do ensino fundamental, mas pode ser utilizado como estratégia de reforço de aprendizagem para alunos de outros anos/séries.

O jogo não é auto explicativo, apresenta a necessidade da intervenção de um instrutor para que a criança entenda o que fazer.

A quantidade de cores/resposta é limitada a 3 , fazendo com que o aluno não calcule, mas sim, opte pela tentativa e erro, pois o programa indica o erro.

Ponto positivo do aplicativo indica a resposta errada e dá a chance de refazer o desafio permitindo-o pensar e até usar de material concreto para efetivar a resposta a ser dada, proporcionando aprendizagem. O aplicativo corresponde ao propósito de ser utilizado com estratégia de aprendizagem apenas como estratégia de iniciação ao conteúdo, os desafios permitem vício de resposta.

\section{Matemática Pacman}

https://www.cokitos.pt/matematicapacman/play/

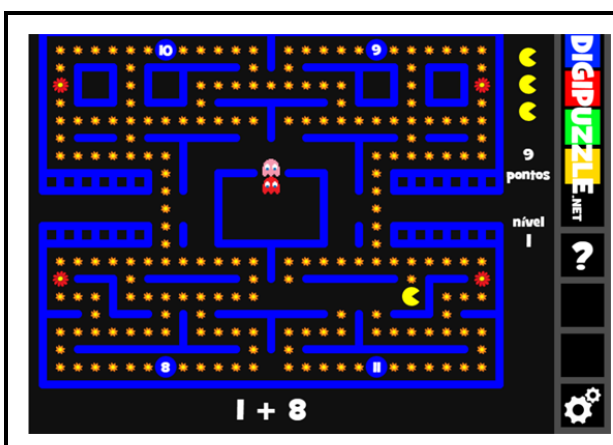

Este aplicativo cumpre com seu propósito proporcionando, a criança, desenvolver raciocínio lógico matemático, atenção, concentração e compreender o processo da adição e subtração. O aplicativo disponibiliza vários desafios em um design chamativo pelo estilo game, despertando a curiosidade da criança.

Além de desenvolver o raciocínio, também requer habilidade motora, noção de espaço e direção, a dificuldade dos desafios pode ser programada, possibilitando uma melhor observação do interventor e aprendizagem por parte dos alunos.

O jogo não é auto explicativo, apresenta a necessidade da intervenção de um instrutor para que a criança entenda o que fazer, porém, alguns alunos já conhecem a lógica do game. O ponto negativo do jogo está na perda de vidas devido ao erro no cálculo, sem a chance de refazer a operação e a falta de acesso a resposta correta.

O programa também pode ser utilizado para atividades em pares ou equipes, necessitando de poucas adaptações.

O aplicativo corresponde ao propósito de ser utilizado com estratégia de aprendizagem, porém, deve ser dada atenção especial aos alunos que apresentam dificuldades motoras.

\section{4ํ e 5ํ Princípios da Contagem}

Irrelevância da ordem - objetos de um dado conjunto podem ser contados em qualquer ordem.

Abstração - objetos de qualquer natureza podem ser contados juntos. 


\section{Quadro 4 - Ferramentas analisadas para o $4^{\circ}$} e 5o Princípio

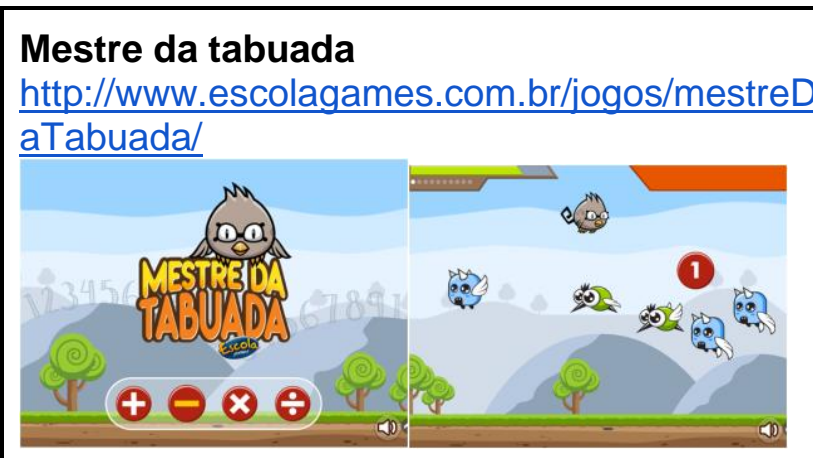

Este aplicativo proporciona, a criança, desenvolver raciocínio lógico matemático, atenção e concentração, porém, não é um jogo atrativo, sua dinâmica é cansativa resultando no desinteresse e desistência da criança.

Além de trabalhar o raciocínio, também requer habilidade motora, noção de espaço e direção, o jogo permite a chance de refazer a operação mas a indicação de erro ficou difícil de ser entendida pela criança. O aplicativo disponibiliza desafios, além de mostrar a tabuada de todas as operações, podendo ser utilizado no formato de quiz.

O app não corresponde ao propósito de ser utilizado com estratégia de aprendizagem.

\section{Completar Soma e Subtração}

https://www.cokitos.pt/completar-adicao-esubtracao/play/

Completar Soma e Subtração

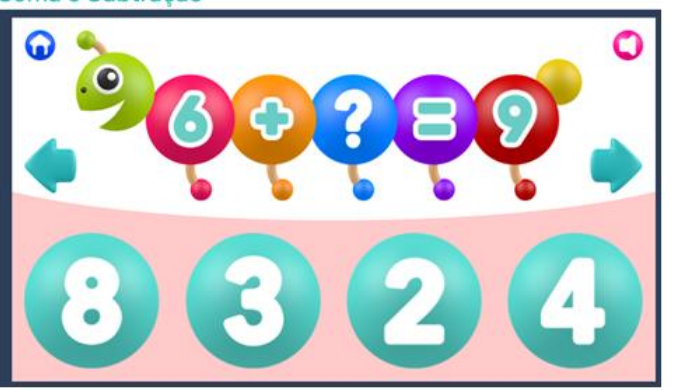

Este aplicativo proporciona, a criança, desenvolver raciocínio lógico matemático, atenção e concentração, porém, poderia ser ainda mais atrativo.

O jogo corrige interativamente sua resposta no local, marcando a correta com verde e a resposta incorreta com uma cruz vermelha.Permite 4 opções de resposta, dando a chance de refazer a operação até chegar no cálculo correto.

O desafio disponibilizado pelo aplicativo não se atualiza, e não apresenta a possibilidade de evolução de níveis.

O app corresponde ao propósito de ser utilizado com estratégia de aprendizagem, porém, recomendo utilizá-lo para alunos do pré e $1^{\circ}$ ano do Ensino Fundamental.

\section{Jogo de Raciocínio Lógico: Blinky II}

https://www.cokitos.pt/jogo-de-raciocinio-

logico-blinky-ii/play/

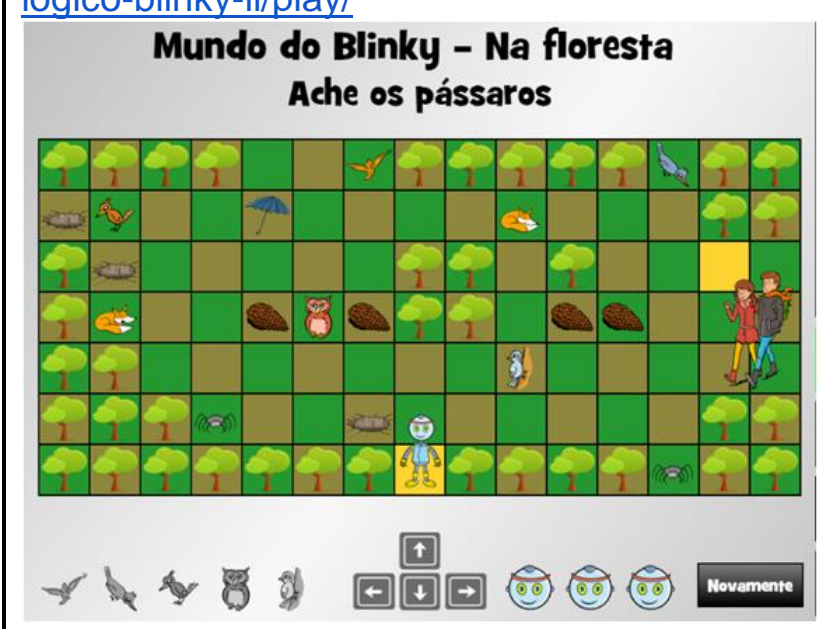

Neste jogo de raciocínio lógico o robô tem a missão de encontrar os objetos que aparecem abaixo na tela. A criança tem que dirigir o robô com os controles, desviando dos obstáculos e inimigos, montando uma trajetória segura para cumprir a missão. Um jogo de lógica, inteligência e raciocínio.

O programa também pode ser utilizado para atividades em pares ou equipes. $O$ app corresponde ao propósito de ser utilizado com estratégia de aprendizagem, e objeto auxiliador na detecção de dificuldades nas habilidades motoras, lateralidade e espaço, devendo ser dada atenção especial aos alunos que apresentarem estas particularidades. Para a resolução de jogos de lógica, é necessária a intervenção de um instrutor para explicar à criança qual é o objetivo e a missão do jogo. 


\section{CONSIDERAÇÕES FINAIS}

Conclui-se que tal tendência tecnológica na construção destes princípios, é coerente com a literatura pesquisada e sugere-se a aplicação dos jogos didáticos virtuais e apps para auxiliar na assimilação dos mesmos aliado a uma intervenção pedagógica eficaz para crianças desta faixa etária, considerando-se a importância da aprendizagem dos princípios da contagem para as aprendizagens matemáticas posteriores.

Considerou-se que os jogos possibilitam atividades para exercício da memória e consequentemente a fixação de conteúdos voltados às atividades criadoras, e à imaginação. Corrobora com esta afirmação, Vygotsky [13], quando afirma que:

"O jogo da criança não é uma recordação simples do vivido, mas sim a transformação criadora das impressões para a formação de uma nova realidade que responda às exigências e inclinações dela mesma".

Deste modo, no espaço escolar, o jogo pode ser um veículo para o aprimoramento do potencial social, emocional e intelectual dos alunos, o que contribui para o desenvolvimento das funções psicológicas superiores. Essas funções são consideradas a base para a formulação de pensamentos complexos necessários para a aprendizagem do currículo, ou seja, aquelas funções mentais que caracterizam 0 comportamento consciente do homem, sejam elas: raciocínio lógico, memória, atenção voluntária, concentração, tempo de reação, e percepção.

Presume-se que formas de trabalho convencionais de aplicação dos objetos de conhecimento, nem sempre garantem que o aluno consiga absorver várias informações, e que estes objetos serão efetivamente significativos na sua vida escolar, de acordo com Silva [14]

[...] O indivíduo faz uma série de atividades préestabelecidas, presume-se que esteja assimilando todo tema transmitido em sala, onde na verdade ele está apenas condicionando o assunto. Dessa forma, atividades que potencializam o aprendizado de forma prazerosa vêm se confirmando cada vez mais como método eficiente SILVA [14].

Quanto ao processo de observação, na pesquisa em questão respondemos os cinco questionamentos positivamente pois a aluna evoluiu e atingiu os quatro níveis descritos, sendo eles:

Nível 1 - Verificar se o aluno pode contar e quantificar, mas sem precisar relacionar 0 número à quantidade. (Princípio da contagem termo a termo)

Nível 2 - Verificar se os alunos construíram uma série de contagem mental que requer a compreensão de números e quantidades. (Princípio da contagem ordem estável)

Nível 3 - Verificar se os alunos são capazes de trabalhar simultaneamente com duas séries de contagem mental, adicionando e subtraindo dezenas de unidades. (Princípio

da contagem cardinalidade)

Nível 4 - Verificar se os alunos podem estender a sua compreensão de dezenas e unidades para todo o sistema numérico. (Princípio da contagem irrelevância da ordem e abstração).

Como forma de recuperar ou fazer o aluno se apropriar de conceitos, a sugestão dos jogos listados abaixo informa os títulos que permitem a quantificação de objetos ( de forma mental ou concreta), também permitem que o aluno ordene os números corretamente, e que façam a correspondência do número contado com o total de objetos. Os jogos também permitem que 0 aluno, ao relacionar a disposição dos objetos ou ausência dos mesmos, compreenda que esta situação não altera seu valor. Assim sendo, todos os jogos listados abaixo podem ser utilizados como ferramentas estratégicas de ensino/aprendizagem, pois, se adéquam aos cinco princípios abordados nesta pesquisa. Respondendo à pergunta inicial que motivou esta pesquisa "Os Jogos Virtuais auxiliam na consolidação das habilidades relacionadas aos Princípios da Contagem na alfabetização matemática?"

Sim, o emprego do jogo didático virtual como recurso pedagógico demonstra ser uma atividade interessante, rica e eficaz, envolvendo ações que auxiliam na aprendizagem e 
consolidação dos princípios da contagem, devido ao impulso natural do estudante mediante a ação de jogar e a capacidade de envolvê-lo de maneira intensa e total. O jogo funciona como complemento das aulas convencionais, quando provoca o desenvolvimento cognitivo, pois, as aulas diferenciadas facilitam a fixação do conteúdo.

Buscou-se, assim, favorecer a aprendizagem da aluna por meio de experiências novas de ensino com o uso de tecnologias.

\section{REFERENCIAS}

[1] Gelman R, Gallistel CR. The child's understanding of number. Cambridge: Harvard University Press; 1978

[2] KAMII. Constance. A criança e o número: implicações da teoria de Piaget. Campinas: Papirus, 1990.

[3] BORIN,J. Jogos e resolução de problemas: uma estratégia para as aulas de matemática. São Paulo: IME-USP;1996.

[4] BRASIL. Ministério da Educação. Secretaria de Educação Básica. Base Nacional Comum Curricular: Educação é a Base. Brasília: MEC; SEB, 2018. Disponível em:<http://basenacionalcomum.mec.gov.br/abase>. Acesso em: 05 jun. 2020.

[5] NUNES, T.; BRYANT, P. Crianças fazendo Matemática. Tradução de: COSTA, S. Porto Alegre: Artes Médicas, 1997.

[6] YIN, R. K. Estudo de caso: planejamento e métodos. 5. ed. Porto Alegre: Bookman, 2015.

[7] PIAGET, J.; SZEMINSKA, A. A gênese do número na criança. 3 . ed. Tradução de: OITICICA, C. M. Rio de Janeiro: Zahar, 1981.

[8] Geary, David C. Matemática e dificuldades de aprendizagem. https://doi.org/10.1177/002221940403700102 01

[9] Todos pela educação. Relatório de Atividades do ano de 2012 do movimento Todos Pela Educação. Disponível em: https://todospelaeducacao.org.br/wordpress/ wp-content/uploads/2020/08/relatorio-deatividades-2012.pdf, Acessado Outubro de 2020.

[10] MACEDO, L; PETTY, A. L. S; Passos, N. C; Os jogos e o lúdico na aprendizagem escolar. Porto Alegre: Artmed, 2005.

[11] Fontes, REJANE DE SOUZA ; Ensino Colaborativo: Uma Proposta de Educação Inclusiva. Araraquara, SP: Junqueira \& Marin, 2009.

[12] GIL, A. C. Métodos e técnicas de pesquisa social. 5.ed. São Paulo: Atlas, 1999.

[13] VYGOTSKY, Lev Semionovitch. Imaginação e criatividade na infância. Tradução de João Pedro Fróis. São Paulo: WMF Martins Fontes, 2014. 125 p.

[14] SILVA, E. G.; SANTOS, S. L. CAMPOS, A. G.; OLIVEIRA, D. I. F.; ALMEIDA, L. I. M. V. Jogos Interativos: uma abordagem metodológica para auxiliar no processo ensino aprendizagem dos alunos do $6^{\circ}$ e $7^{\circ}$ anos na Escola Campos Sales em Juscimeira/MT. Revista Monografias Ambientais, Santa Maria, RS, v. 14, p. 23-40, 2015. 